\title{
Prognostic Factors Influencing Infectious Complications after Cytoreductive Surgery and HIPEC: Results from a Tertiary Referral Center
}

\author{
Maurizio Cardi (D), ${ }^{1}$ Simone Sibio $\left(D,{ }^{1}\right.$ Francesco Di Marzo, ${ }^{2}$ Francesco Lefoche, ${ }^{3}$ \\ Claudia d'Agostino, ${ }^{3}$ Giovanni Battista Fonsi, ${ }^{1}$ Giuseppe La Torre, ${ }^{4}$ Ludovica Carbonari, ${ }^{1}$ \\ and Paolo Sammartino ${ }^{1}$ \\ ${ }^{1}$ Dipartimento di Chirurgia Pietro Valdoni, Sapienza Università di Roma, Viale del Policlinico 155, 00161 Roma, Italy \\ ${ }^{2}$ Chirurgia Generale, Ospedale Versilia, Via Aurelia 335, 55041 Lido di Camaiore, Italy \\ ${ }^{3}$ Dipartimento di Malattie Infettive e Tropicali, Sapienza Università di Roma, Viale del Policlinico 155, 00161 Roma, Italy \\ ${ }^{4}$ Dipartimento di Sanità Pubblica e Malattie Infettive, Sapienza Università di Roma, Viale del Policlinico 155, 00161 Roma, Italy \\ Correspondence should be addressed to Maurizio Cardi; maurizio.cardi@uniroma1.it
}

Received 4 October 2018; Revised 12 December 2018; Accepted 13 February 2019; Published 2 May 2019

Academic Editor: Martin Hubner

Copyright (C) 2019 Maurizio Cardi et al. This is an open access article distributed under the Creative Commons Attribution License, which permits unrestricted use, distribution, and reproduction in any medium, provided the original work is properly cited.

\begin{abstract}
Background. Cytoreductive surgery (CRS) and hyperthermic intraperitoneal chemotherapy (HIPEC) showed promising results in selected patients. High morbidity restrains its wide application. The aim of this study was to report postoperative infectious complications and investigate possible correlations with the preoperative nutritional status and other prognostic factors in patients with peritoneal metastases treated with CRS and HIPEC. Methods. For the study, we reviewed the clinical records of all patients with peritoneal metastases from different primary cancers treated with CRS and HIPEC in our Institution from November 2000 to December 2017. Patients were divided according to their nutritional status (SGA) into groups A (wellnourished) and B/C (mild or severely malnourished, respectively). Possible statistical correlations between risk factors and postoperative complication rates have been investigated by univariate and multivariate analysis. Results. Two hundred patients were selected and underwent CRS and HIPEC during the study period. Postoperative complications occurred in $44 \%$ of the patients, $35.3 \%$ in SGA-A patients, and 53\% in SGA-B/C patients. Cause of complications was infective in 42, noninfective in 37 , and HIPEC related in 9 patients. Infectious complications occurred more frequently in SGA-B/C patients $(32.6 \%$ vs. $9.8 \%$ of SGA-A patients). The most frequent sites of infection were surgical site infections (SSI, 35.7\%) and central line-associated bloodstream infections (CLABSI, 26.2\%). The most frequent isolated species was Candida (22.8\%). ASA score, blood loss, performance status, PCI, large bowel resection, postoperative serum albumin levels, and nutritional status correlated with higher risk for postoperative infectious complications. Conclusions. Malnourished patients undergoing cytoreductive surgery and hyperthermic intraperitoneal chemotherapy are more prone to postoperative infectious complications, and adequate perioperative nutritional support should be considered, including immune-enhancing nutrition. Sequential monitoring of common sites of infection, antifungal prevention of candidiasis, and careful patient selection should be implemented to reduce the complication rate.
\end{abstract}

\section{Introduction}

Peritoneal metastases have long been considered a terminal event in the natural history of many gynecological and gastrointestinal (GI) cancers [1,2], and the role of surgery for patients with peritoneal surface malignancies has been mostly palliation for tumor-related complications. Since the introduction of cytoreductive surgery (CRS) and hyperthermic intraperitoneal chemotherapy (HIPEC) by Sugarbaker in the early 90s [3], this treatment has expanded [4-13]. Despite promising results, these complex surgical procedures carry high rates of postoperative complications and 
mortality, restraining the wide diffusion and feasibility of these techniques $[10,11,14-16]$.

A number of studies extensively report surgical and HIPEC-related complications, but only few of them are focused on postoperative infectious complications $[2,17-$ 20]. Moreover, nutritional status has been shown to have a great impact on the immune system making patients with impaired host immune response more susceptible to postoperative complications after gastrointestinal surgery [21-24] including patients with ovarian and advanced colorectal cancer $[25,26]$, but the literature still lacks data about the impact of nutritional status in the outcome of patients treated with CRS and HIPEC for peritoneal carcinomatosis.

This is why we critically reviewed our Institution's clinical database of the patients who underwent CRS and HIPEC for peritoneal metastases with the aim to investigate correlations between possible prognostic factors and postoperative infectious complications, focusing on nutritional status and type of surgical procedures.

\section{Materials and Methods}

Patients with the diagnosis of peritoneal metastases from different primary cancers treated with cytoreductive surgery and HIPEC were selected from a prospectively maintained database in our Institution during a 17-year period from November 2000 to December 2017. Inclusion criteria were as follows: confirmed peritoneal metastases (histologically and/or cytologically); age $<75$ years; ECOG performance status 0-2 [27]; adequate renal, liver, and bone marrow function; resectable disease; and preoperative serum albumin level $>2$ $\mathrm{g} / \mathrm{dl}$. All patients had a Body Mass Index (BMI) between 18.50 and $24.99 \mathrm{~kg} / \mathrm{m}^{2}$, a range that defines the normal weight population. We excluded from the study patients with extra abdominal metastases and/or unresectable disease. Nutritional status was evaluated as a risk factor for the development of infectious complications and assessed by providing each patient with a Subjective Global Assessment (SGA) form [17]. Patients were classified into 3 groups: well nourished (A), mildly moderately malnourished (B), and severely malnourished (C). BMI, albumin level, and cholesterol as well as triglycerides levels were considered to assess the need for Total Parenteral Nutrition (TPN) support prior to surgery. Mildly (B) or severely (C) malnourished patients received a minimum of 15 days of TPN and vitamin supplementation.

All patients received antibiotic prophylaxis at induction of anesthesia, with $2 \mathrm{~g}$ iv of ceftriaxone and $500 \mathrm{mg}$ iv of metronidazole, repeated every 4 hours during the procedure and 24 hours after surgery.

Surgical procedures and HIPEC techniques have been described in previous reports $[3,10]$. The extent of peritoneal disease and results of cytoreduction were classified using the peritoneal cancer index (PCI) and completeness of cytoreduction score (CC score) according to Sugarbaker [28]. According to protocols in use in our Institution, the drug used for HIPEC in 112 patients with gynecologic (ovarian, endometrial, or breast) primary cancers was cisplatin $\left(75 \mathrm{mg} / \mathrm{m}^{2}\right)$, while in 79 patients with colorectal, gastric, and pseudomyxoma peritonei, the drug was oxaliplatin ( $460 \mathrm{mg} / \mathrm{m}^{2}$ in $2 \mathrm{l} / \mathrm{m}^{2}$ of dextrose solution) plus intravenous infusion of 5-FU $\left(400 \mathrm{mg} / \mathrm{m}^{2}\right)$. The 9 cases of mesothelioma underwent cisplatin and doxorubicin. Patients were sent to the intensive care unit (ICU) in the immediate postoperative period for at least 24 hours.

In all symptomatic patients with suspected infection (fever $>38^{\circ} \mathrm{C}$, dyspnea, dysuria, purulent surgical wound or drain, increasing white cell count, and C-reactive proteinCRP levels), blood cultures (a total of 3 samples, taken every $30 \mathrm{~min}$ from both central venous lines (CVLs) and the peripheral vein) and culture of the CVL tip and of biological fluids including those from abdominal drainage and urine cultures were performed. In case of sepsis from intraabdominal infection, an abdominal CT scan or ultrasound was carried out to rule out and eventually to drain an intraabdominal fluid collection.

An empiric antimicrobial therapy with carbapenem and teicoplanin was started until microbiologic results were obtained. Antifungal therapy was associated when a fungal infection was also suspected. Infected CVLs were removed and replaced 48/72 hours after the beginning of the therapy. Removal of the bladder catheter was mandatory after Candida contamination was proven. Once infection resolved, antimicrobial drug washout was performed for at least 24 hours, followed by blood cultures and urinalysis. No further investigations were carried out in the case of symptom-free patients.

For each patient, we recorded demographic, clinical, and pathological data: age, sex, comorbidities, nutritional status assessment, type of primary tumor, ECOG performance status, ASA score, time of cytoreduction (primary or secondary), preoperative chemotherapy, type and length of surgical procedures, PCI and CC score, blood loss, length of ICU, and overall postoperative stay. Observed postoperative adverse events have been recorded and divided as infectious, surgical, or HIPEC-related and graded according to the National Cancer Institute Common Terminology Criteria for Adverse Events (CTCAE) 5.0 [29]. The WHO chemotherapy toxicity scale was used to score cisplatin toxicity [30]. In the case of infectious complications, site of infection, type of sample collected, and etiology of the infection were recorded.

Possible statistical correlations between risk factors and postoperative complications rates have been investigated by the mean of univariate analysis (log-rank test). Results were matched by the mean of multivariate analysis (Cox regression model) to identify independent variables influencing infections occurring, using the Statistical Package for the Social Sciences for Windows (SPSS GmbH, Munich, Germany). The 2 -tailed $p$ values below 0.05 were considered statistically significant.

\section{Results}

During the considered study period, out of 421 patients who underwent CRS+HIPEC for peritoneal surface malignancies in our Institution, we selected 200 patients who fulfilled the inclusion criteria. We excluded 77 patients for high 
BMI, 74 with an ECOG PS > 2, 41 for incomplete records, and 29 because of age. Forty-three were male and 157 female. Mean age was 61.3 years (range $32-75$ ). Clinical characteristics are reported in Table 1. One hundred and four patients had previous chemotherapy regimens. Twenty-eight primary advanced ovarian cancers underwent neoadjuvant treatment with a platinum/paclitaxel-based regimen. Of the remaining 76 patients, 6 had systemic chemotherapy for breast cancer several years before developing peritoneal metastases; 52 patients with peritoneal metastases from colorectal cancer had previous (from 1 to 5 years before) FOLFOX/FOLFIRI regimens. The remaining 18 patients (gastric and endometrial cancers) underwent neoadjuvant chemotherapy before cytoreduction. All patients were admitted for surgery at least two months after the end of the last chemotherapy regimen and after having proven their immune competency by blood tests. In order to achieve maximal cytoreduction, a total of 1360 surgical procedures were performed (Table 1).

An uneventful recovery was observed in 112 cases (56\%). Postoperative complications were observed in 88 patients (44\%). Cause of complications was infective-related in 42 , noninfective-related in 37, and HIPEC-related in 9 patients. Mortality rate was 3.5\%. Causes of death were sepsis and subsequent multiorgan failure in 2 patients, complications of an intra-abdominal abscess in 1 patient, and massive pulmonary embolism despite a preoperative prophylactic low molecularweight heparin standard protocol in use in our Institution in 2 patients. The remaining 2 patients died of myocardial infarction (1) and of complications after bowel perforation (1).

Major complications (grades 3 to 4 ) occurred in 30 patients (15\%), requiring interventional endoscopy or CT scan/ultrasound-guided procedures, surgery, or readmission in the ICU. Type and grade of the observed adverse events are reported in Table 2. Etiology of infectious complications was bacterial in 26, fungal in 6 , and mixed bacterial/fungal in 10 cases. Candida spp were the most frequent species isolated, followed by E. coli, Klebsiella, and Staphylococcus epidermidis. Sixty-two positive cultures were reported in the 42 patients with infectious complications. Etiology and site of complication are reported in Table 3.

Complications were observed in 36 of 102 (35.3\%) of the patients in the SGA group A and in 52 of 98 (53\%) of the patients in SGA groups B/C $(p<0.05)$ while no statistical difference was observed for major complications in the 2 groups ( $13.7 \%$ in group A vs. $23.4 \%$ in groups $\mathrm{B} / \mathrm{C}, p$ : ns). The infectious complication rate was higher in SGA groups $\mathrm{B} / \mathrm{C}$ than in SGA group A $(9.8 \%$ vs. $32.6 \%, p<0.01)$.

Infectious complications occurred in 30 cases in a single site or organ, in 12 patients in multiple sites, 2 of which led to septic shock and death. Infection was the only complication in 14 patients and in 28 was associated with a surgical complication. A simultaneous infection occurred in 16 of the 58 patients $(27.5 \%)$ with only one postoperative surgical complication and in 12 of the 16 patients (75\%) in whom multiple postoperative surgical complications occurred $(p<0.003)$.

Univariate analysis performed to correlate possible risk factors and incidence of postoperative infective adverse events showed that ASA score, performance status, SGA, PCI, intraoperative blood loss, large bowel resection, and
TABLE 1: Clinical characteristics.

\begin{tabular}{|c|c|c|c|}
\hline Variables & Categories & $N$ & $\%$ \\
\hline \multirow{3}{*}{ ASA score } & 1 & 96 & 48 \\
\hline & 2 & 88 & 44 \\
\hline & 3 & 16 & 8 \\
\hline \multirow{2}{*}{$\begin{array}{l}\text { Performance } \\
\text { status (ECOG) }\end{array}$} & 0 & 67 & 33.5 \\
\hline & $1-2$ & 133 & 66.5 \\
\hline \multirow{3}{*}{ SGA score } & $\mathrm{A}$ & 102 & 51 \\
\hline & $\mathrm{B}$ & 78 & 39 \\
\hline & $\mathrm{C}$ & 20 & 10 \\
\hline \multirow{7}{*}{ Primary tumor } & Ovarian & 101 & 50.5 \\
\hline & Colorectal & 52 & 26 \\
\hline & Gastric & 16 & 8 \\
\hline & Pseudomyxoma peritonei & 11 & 5.5 \\
\hline & Malignant mesothelioma & 9 & 4.5 \\
\hline & Breast & 6 & 3 \\
\hline & Endometrial & 5 & 2.5 \\
\hline $\begin{array}{l}\text { Peritoneal cancer } \\
\text { index (PCI) }\end{array}$ & Mean (range) & $16.5(6-29)$ & - \\
\hline \multirow{17}{*}{$\begin{array}{l}\text { Surgical } \\
\text { procedure } \\
\text { (tot. 1360) }\end{array}$} & Regional lymphadenectomy & 198 & - \\
\hline & Omentectomy & 186 & - \\
\hline & Implant excisions & 164 & - \\
\hline & Total/subtotal parietal & 162 & - \\
\hline & Peritonectomy & & - \\
\hline & Colorectal resections & 138 & - \\
\hline & $\begin{array}{l}\text { Hysterectomy and } \\
\text { ovariectomy }\end{array}$ & 118 & \\
\hline & Splenectomy & 82 & - \\
\hline & Cholecystectomy & 74 & - \\
\hline & Abdominal wall resections & 50 & - \\
\hline & Appendectomy & 48 & - \\
\hline & Small bowel resections & 40 & - \\
\hline & Pelvic mass excisions & 26 & - \\
\hline & Bladder resections & 12 & - \\
\hline & Liver resections & 10 & - \\
\hline & Gastric resections & 4 & - \\
\hline & Other & 48 & - \\
\hline \multirow{3}{*}{$\begin{array}{l}\text { Completeness } \\
\text { of cytoreduction } \\
\text { (CC) }\end{array}$} & $\mathrm{CC} 0$ & 134 & 67 \\
\hline & $\mathrm{CC} 1$ & 42 & 21 \\
\hline & $\mathrm{CC} 2 / 3$ & 24 & 12 \\
\hline
\end{tabular}

postoperative serum albumin level were factors significantly influencing postoperative infection rates (Table 4). Multivariate analysis (Cox regression test) confirmed the ASA score, intraoperative blood loss, large bowel resection, and SGA as independent variables significantly linked with postoperative infectious complications (Table 5).

\section{Discussion}

Mortality and morbidity rates after cytoreduction and HIPEC vary greatly in the literature $[2,5,31]$. Possible reasons 
TABLE 2: Postoperative adverse events (as graded by CTCAE severity score v 5.0).

\begin{tabular}{|c|c|c|c|c|c|c|}
\hline Adverse events & $N$ & $\%$ & Grade $1 / 2$ & Grade 3 & Grade 4 & Grade 5 \\
\hline HIPEC-related & 9 & 10.2 & 9 & - & - & - \\
\hline Renal & 6 & & 6 & - & - & - \\
\hline Hematological & 3 & & 3 & - & - & - \\
\hline Infectious complications & 42 & 47.7 & 31 & 7 & 1 & 3 \\
\hline Sepsis & 2 & & - & - & - & 2 \\
\hline Abdominal abscess & 8 & & - & 7 & - & 1 \\
\hline Central line-associated bloodstream infections & 11 & & 11 & - & - & - \\
\hline Wound infection & 15 & & 15 & - & - & - \\
\hline Pneumonia & 6 & & 5 & - & 1 & - \\
\hline Noninfectious complications & 37 & 42.1 & 11 & 11 & 11 & 4 \\
\hline Acute postoperative pancreatitis & 4 & & - & 3 & 1 & - \\
\hline Pleural effusion & 10 & & 7 & 3 & - & - \\
\hline Deep vein thrombosis & 2 & & 2 & - & - & - \\
\hline Transient ischemic attack & 1 & & - & - & 1 & - \\
\hline Pulmonary embolism & 2 & & - & - & - & 2 \\
\hline Respiratory failure & 4 & & 2 & - & 2 & - \\
\hline Bowel perforation & 4 & & - & - & 3 & 1 \\
\hline Anastomotic dehiscence & 1 & & - & - & 1 & - \\
\hline Colostomy necrosis & 1 & & - & - & 1 & - \\
\hline Urinary fistula & 2 & & - & 2 & - & - \\
\hline Peritoneal bleeding & 2 & & - & 2 & - & - \\
\hline Gastric bleeding & 1 & & - & 1 & - & - \\
\hline Acute myocardial infarction & 3 & & - & - & 2 & 1 \\
\hline Total & 88 & & $51(57.9 \%)$ & $18(20.4 \%)$ & $12(13.6 \%)$ & $7(0.8 \%)$ \\
\hline
\end{tabular}

TABLE 3: Site and etiology of infectious complications.

\begin{tabular}{|c|c|c|c|c|c|c|c|}
\hline & Wound & Abdominal drain & CVL & Bloodstream & Vaginal & Urine & Total \\
\hline Candida albicans & 0 & 2 & 5 & 6 & 2 & 1 & 16 \\
\hline Escherichia coli & 6 & 4 & 0 & 0 & 1 & 1 & 12 \\
\hline Klebsiella pneumonie & 2 & 1 & 3 & 1 & 0 & 1 & 8 \\
\hline Enterobacter & 2 & 4 & 0 & 0 & 0 & 0 & 6 \\
\hline Staphylococcus aureus & 4 & 2 & 0 & 0 & 0 & 0 & 6 \\
\hline Staphylococcus coag neg & 0 & 0 & 2 & 2 & 0 & 0 & 4 \\
\hline Enterococcus faecalis & 2 & 2 & 0 & 0 & 0 & 0 & 4 \\
\hline Proteus mirabilis & 0 & 0 & 0 & 0 & 2 & 0 & 2 \\
\hline Acinetobacter baumannii & 0 & 0 & 1 & 1 & 0 & 0 & 2 \\
\hline Pseudomonas aeruginosa & 2 & 0 & 0 & 0 & 0 & 0 & 2 \\
\hline Total & 18 & 15 & 11 & 10 & 5 & 3 & 62 \\
\hline
\end{tabular}

could be that the definition and management themselves are subjective, often depending on the surgeon's attitude and skills [5] and that different complication classifications are currently used $[11,32]$. It would be very important to standardize the adverse events reported in the literature, and the use of the NCI-CTCAE could be helpful to report adverse events in a homogeneous way to be easily compared.

Regarding type of operation, often cytoreductive surgery procedures include multiple bowel resections in the attempt to obtain a CC- 0 score, and interestingly, our results identify colorectal resections as a variable influencing the postoperative infection rate. This should be carefully considered during planning of surgical strategy, avoiding large bowel resections in favor of more conservative surgical choices to reduce the risk of postoperative infectious adverse events.

Mortality (3.5\%) and morbidity (44\%) reported in our series match with those reported in previous studies $[6,10$, $11,17,32,33]$. Quenet et al. recently reported the results of the PRODIGE-7 trial with a HIPEC-related 60-day major morbidity (grades 3-5) of $24.1 \%$ [34]. We observed an 
TABLE 4: Correlation between risk factors and infectious complications (univariate analysis).

\begin{tabular}{|c|c|c|c|}
\hline Variables & $\begin{array}{c}\text { Patients }(n=200) \\
(\%)\end{array}$ & $\begin{array}{l}\text { Infectious } \\
\text { complication } \\
(n=42)(\%)\end{array}$ & $p$ \\
\hline \multicolumn{4}{|l|}{ Age (years) } \\
\hline$<61$ & $82(41)$ & $19(45)$ & 0.06 \\
\hline$>61$ & $118(59)$ & $23(55)$ & \\
\hline \multicolumn{4}{|l|}{ ASA score } \\
\hline$<3$ & $184(92)$ & $12(28)$ & $0.018^{*}$ \\
\hline$>3$ & $16(8)$ & $30(72)$ & \\
\hline \multicolumn{4}{|l|}{ SGA score } \\
\hline A & $102(51)$ & $11(26)$ & $0.016^{*}$ \\
\hline $\mathrm{B} / \mathrm{C}$ & $98(49)$ & $31(74)$ & \\
\hline \multicolumn{4}{|c|}{ P. status (ECOG) } \\
\hline$<2$ & $107(53)$ & $15(36)$ & $0.03^{*}$ \\
\hline$>2$ & $93(47)$ & $27(64)$ & \\
\hline \multicolumn{4}{|l|}{ Cytoreduction } \\
\hline Primary & $124(62)$ & $20(48)$ & 0.1 \\
\hline Secondary & $76(38)$ & $22(52)$ & \\
\hline \multicolumn{4}{|l|}{ PCI score } \\
\hline$<15$ & $62(31)$ & $16(38)$ & $0.05^{*}$ \\
\hline$>15$ & $138(69)$ & $26(62)$ & \\
\hline \multicolumn{4}{|l|}{ Ascites } \\
\hline Yes & $92(46)$ & $23(55)$ & 0.06 \\
\hline No & $108(54)$ & $19(45)$ & \\
\hline \multicolumn{4}{|c|}{ Prev. chemotherapy } \\
\hline Yes & $104(52)$ & $24(57)$ & 0.07 \\
\hline No & $96(48)$ & $18(43)$ & \\
\hline \multicolumn{4}{|l|}{$\begin{array}{l}\text { Intestinal } \\
\text { obstruction }\end{array}$} \\
\hline Yes & $42(21)$ & $20(48)$ & 0.1 \\
\hline No & $158(79)$ & $22(52)$ & \\
\hline \multicolumn{4}{|l|}{$\begin{array}{l}\text { Colorectal } \\
\text { resections }\end{array}$} \\
\hline Yes & $138(69)$ & $28(67)$ & $0.024^{*}$ \\
\hline No & $62(31)$ & $14(33)$ & \\
\hline \multicolumn{4}{|c|}{$\begin{array}{l}\text { Length of surgical } \\
\text { procedure (min) }\end{array}$} \\
\hline$<423$ & $159(79.5)$ & $17(40)$ & 0.059 \\
\hline$>423$ & $41(20.5)$ & $25(60)$ & \\
\hline \multicolumn{4}{|c|}{$\begin{array}{l}\text { Number of surgical } \\
\text { procedures }\end{array}$} \\
\hline$<4$ & $18(9)$ & $18(43)$ & 0.07 \\
\hline$>4$ & $182(91)$ & $24(57)$ & \\
\hline \multicolumn{4}{|c|}{ Blood loss (ml) } \\
\hline$<1400$ & $93(46.5)$ & $13(31)$ & $0.04^{*}$ \\
\hline$>1400$ & $107(53.5)$ & $29(69)$ & \\
\hline \multicolumn{4}{|c|}{ ICU stay (hours) } \\
\hline$<31$ & $78(39)$ & $17(40)$ & 0.059 \\
\hline$>31$ & $122(61)$ & $25(60)$ & \\
\hline
\end{tabular}

TABLE 4: Continued.

\begin{tabular}{lccc}
\hline Variables & $\begin{array}{c}\text { Patients }(n=200) \\
(\%)\end{array}$ & $\begin{array}{c}\text { Infectious } \\
\text { complication } \\
(n=42)(\%)\end{array}$ & $p$ \\
\hline $\begin{array}{l}\text { HIPEC drugs } \\
\text { Cisplatin }\end{array}$ & $132(66)$ & $20(48)$ & 0.1 \\
$\quad$ Oxaliplatin & $68(34)$ & $22(52)$ & \\
$\begin{array}{l}\text { Post-op serum } \\
\text { albumin (g/dl) }\end{array}$ & & & \\
$<2$ & $54(27)$ & $29(69)$ & $0.03^{*}$ \\
$>2$ & $146(73)$ & $13(31)$ & \\
\hline
\end{tabular}

*Significant.

uneventful recovery in $56 \%$ of the patients while 88 patients experienced complications, 51 of them requiring no or only medical treatment (grade 1/2). Grade 3 to 5 adverse events, requiring interventional radiology, reoperation, or ICU readmission, were reported in $18.5 \%$ of the patients. These figures are similar to those reported for other major GI operations $[25,31]$.

In the few previously published studies reporting infectious complications, rates between 24 and $45 \%$ have been observed, with an infection related mortality of $1-2 \%$. Kusamura et al. [6] reported 3.4\% infectious complication rates in 209 peritonectomies followed by HIPEC, and Sugarbaker reported $42 \%$ infection rates in grade III adverse events and $5 \%$ rates in grade IV adverse events. In our series, the most common grade 1-2 infectious complications were surgical site infections and central line-associated bloodstream infections. Intra-abdominal fluid collections were the most frequent major complication (grades 3-5). Despite bacterial infections being more frequent, the Candida species were the most isolated microbial agent. This data confirms a previous report from Capone et al. [2]. Regarding nutritional status, it is crucial to emphasize that.

The importance of perioperative nutritional status in major surgery is well-known [35]. BMI has been shown to be a single clinical variable influencing surgical outcome [36-38], and the serum albumin level is a well-known factor predicting the risk of infectious complications and sepsis $[39,40]$, and recent papers underlined the role of immune stimulating diet or enteral nutrition prior to surgery [41]. In our study, we selected only patients within a normal BMI range to avoid subgroups, underweight or obese, with significant higher mortality and morbidity. Postoperative serum albumin levels $<2 \mathrm{~g} / \mathrm{dl}$ also correlated with higher rates of infectious complications. Infectious complications occurred more frequently in the mildly (B) or severely (C) malnourished group when compared to the group of wellnourished patients (A), highlighting the upmost importance of nutritional status at the time of surgery and the need for an effective perioperative nutritional support.

In patients undergoing cytoreductive surgery and HIPEC, Uccella et al. found malnutrition as a factor predictive of a higher rate of perioperative complications in patients with advanced ovarian cancer undergoing upfront cytoreductive surgery [42], and the results of the clinical trial "Perioperative 
TABLE 5: Risk factors and infectious complications: multivariate analysis (Cox regression model).

\begin{tabular}{|c|c|c|c|c|c|}
\hline Variables & DF & $\begin{array}{l}\text { Sum of } \\
\text { squares }\end{array}$ & $\begin{array}{l}\text { Mean } \\
\text { square }\end{array}$ & $f$ ratio & $\begin{array}{l}\text { Prob. } \\
\text { level }\end{array}$ \\
\hline ASA score & 3 & 2.110112 & 0.7033707 & 4.276 & $0.0072^{*}$ \\
\hline \multicolumn{6}{|l|}{$<3$} \\
\hline \multicolumn{6}{|l|}{$>3$} \\
\hline Blood loss (ml) & 1 & 0.6134862 & 0.6134862 & 3.729 & $0.0466^{*}$ \\
\hline \multicolumn{6}{|l|}{$<1400$} \\
\hline \multicolumn{6}{|l|}{$>1400$} \\
\hline $\begin{array}{l}\text { No. of surgical } \\
\text { procedures }\end{array}$ & 1 & 0.1020328 & 0.1020328 & 0.620 & 0.4330 \\
\hline \multicolumn{6}{|l|}{$<4$} \\
\hline \multicolumn{6}{|l|}{$>4$} \\
\hline Performance status & 3 & 0.1638669 & 5.462231 & 0.332 & 0.8022 \\
\hline \multicolumn{6}{|l|}{$<2$} \\
\hline \multicolumn{6}{|l|}{$>2$} \\
\hline Colonic resections & 2 & 0.6366483 & 0.8336443 & 3.682 & $0.0487^{*}$ \\
\hline \multicolumn{6}{|l|}{ Yes } \\
\hline \multicolumn{6}{|l|}{ No } \\
\hline SGA score & 3 & 0.6246453 & 0.6366483 & 2.994 & $0.0422^{*}$ \\
\hline \multicolumn{6}{|l|}{ A } \\
\hline \multicolumn{6}{|l|}{$\mathrm{B} / \mathrm{C}$} \\
\hline $\begin{array}{l}\text { Platinum-based } \\
\text { HIPEC }\end{array}$ & 1 & 0.1644679 & 0.1664563 & 0.892 & 0.1422 \\
\hline \multicolumn{6}{|l|}{ Cisplatin } \\
\hline \multicolumn{6}{|l|}{ Oxaliplatin } \\
\hline $\begin{array}{l}\text { Serum albumin } \\
\text { levels }(\mathrm{g} / \mathrm{dl})\end{array}$ & 1 & 0.6467919 & 0.7366533 & 2.124 & $0.0382^{*}$ \\
\hline \multicolumn{6}{|l|}{$<2$} \\
\hline$>2$ & & & & & \\
\hline
\end{tabular}

*Significant.

Immunonutrition for Patients Undergoing Cytoreductive Surgery (CRS) and Hyperthermic Intraperitoneal Chemotherapy" from the National Cancer Center of Singapore [43] investigating the impact of immune nutrition in reducing surgical site infections and length of hospital stay should be available in 2019. Early start of enteral or parenteral nutrition and oral feeding seems to be a protective factor towards postoperative complications, and since early postoperative enteral nutrition is not always possible in most of these patients, it has been suggested that early supplementary parenteral nutrition should be given when resuming oral feeding is estimated greater than three days [44]. Standard nutritional support (protein, vitamins, and minerals) and immunonutrition (arginine, nucleotides, and omega 3 fatty acids) seem to both be good options during the perioperative period in order to reduce the length of stay and infectious complications in cancer patients $[45,46]$.

\section{Conclusions}

Malnourished patients (both mild and severely) are more prone to postoperative infectious complications that account for nearly $50 \%$ of all adverse events, and the Candida species are the most frequent infective agent involved. Tumor load (PCI score), ASA score, performance and nutritional status, large bowel resection, and postoperative serum albumin levels were the variables found to significantly influence the rate of postoperative infectious complications in patients in our group of patients with peritoneal metastases undergoing CRS and HIPEC. Adequate perioperative nutritional support including immunonutrition should be considered to reduce postoperative infection rates in these patients.

\section{Data Availability}

The data used to support the findings of this study are available from Simone Sibio upon request.

\section{Conflicts of Interest}

The authors declare that there is no conflict of interest regarding the publication of this paper.

\section{Authors' Contributions}

Maurizio Cardi is the first and corresponding author and was responsible for the original conception and work design, analysis and interpretation of the data, drafting of the work from the first draft through the final version, and the final version draft and approval. Simone Sibio participated to the original study design, intellectual contribution of data analysis, critical review of the final draft, and final version approval. Francesco Di Marzo was responsible for analysis, data interpretation, draft of the parts concerning the nutritional status of the patients and its role as prognostic factors for postoperative infectious complications, critical review, and final version approval. Francesco Lefoche was responsible for the original study conception, analysis, data interpretation, manuscript draft of all aspects concerning the infectious complications part, critical review of the first manuscript draft, and final version approval. Claudia d'Agostino was responsible for data collection, analysis, data interpretation of all aspects concerning the infectious complication part, literature reference research and updating, critical review of the first manuscript draft, and final version approval. Giovanni Battista Fonsi was responsible for the data case collection and draft of the manuscript with particular regard to the HIPEC section and revised the manuscript in all the aspects concerning the HIPEC procedures. The author was also responsible for the critical review and approval of the final version. Giuseppe La Torre was responsible for analysis, data interpretation and draft of all parts regarding the statistical analysis, and critical review of the manuscript draft until approval of the final version. Ludovica Carbonari was responsible for data collection, draft of the various manuscript versions, critical review, and approval of the final version. Paolo Sammartino participated in the original study design and draft of the original manuscript of all surgical aspects and had important intellectual contribution to the manuscript final version that was approved. 


\section{References}

[1] D. Baratti, S. Kusamura, B. Laterza, M. R. Balestra, and M. Deraco, "Early and long-term postoperative management following cytoreductive surgery and hyperthermic intraperitoneal chemotherapy," World Journal of Gastrointestinal Oncology, vol. 2, no. 1, pp. 36-43, 2010.

[2] A. Capone, M. Valle, F. Proietti, O. Federici, A. Garofalo, and N. Petrosillo, "Postoperative infections in cytoreductive surgery with hyperthermic intraperitoneal intraoperative chemotherapy for peritoneal carcinomatosis," Journal of Surgical Oncology, vol. 96, no. 6, pp. 507-513, 2007.

[3] P. H. Sugarbaker, "Peritonectomy procedures," Annals of Surgery, vol. 221, no. 1, pp. 29-42, 1995.

[4] R. M. Smeenk, V. J. Verwaal, N. Antonini, and F. A. N. Zoetmulder, "Progression of pseudomyxoma peritonei after combined modality treatment: management and outcome," Annals of Surgical Oncology, vol. 14, no. 2, pp. 493-499, 2007.

[5] J. Jaehne, "Cytoreductive procedures-strategies to reduce postoperative morbidity and management of surgical complications with special emphasis on anastomotic leaks," Journal of Surgical Oncology, vol. 100, no. 4, pp. 302-305, 2009.

[6] S. Kusamura, R. Younan, D. Baratti et al., "Cytoreductive surgery followed by intraperitoneal hyperthermic perfusion: analysis of morbidity and mortality in 209 peritoneal surface malignancies treated with closed abdomen technique," Cancer, vol. 106, no. 5, pp. 1144-1153, 2006.

[7] P. H. Sugarbaker, "New standard of care for appendiceal epithelial neoplasms and pseudomyxoma peritonei syndrome?," The Lancet Oncology, vol. 7, no. 1, pp. 69-76, 2006.

[8] A. Di Giorgio, E. Naticchioni, D. Biacchi et al., "Cytoreductive surgery (peritonectomy procedures) combined with hyperthermic intraperitoneal chemotherapy (HIPEC) in the treatment of diffuse peritoneal carcinomatosis from ovarian cancer," Cancer, vol. 113, no. 2, pp. 315-325, 2008.

[9] V. J. Verwaal, S. van Ruth, E. de Bree et al., "Randomized trial of cytoreduction and hyperthermic intraperitoneal chemotherapy versus systemic chemotherapy and palliative surgery in patients with peritoneal carcinomatosis of colorectal cancer," Journal of Clinical Oncology, vol. 21, no. 20, pp. 37373743, 2003.

[10] O. Glehen, F. Kwiatkowski, P. H. Sugarbaker et al., "Cytoreductive surgery combined with perioperative intraperitoneal chemotherapy for the management of peritoneal carcinomatosis from colorectal cancer: a multi-institutional study," Journal of Clinical Oncology, vol. 22, no. 16, pp. 3284-3292, 2004.

[11] D. Elias, J. R. Delperro, L. Sideris et al., "Treatment of peritoneal carcinomatosis from colorectal cancer: impact of complete cytoreductive surgery and difficulties in conducting randomized trials," Annals of Surgical Oncology, vol. 11, no. 5, pp. 518-521, 2004.

[12] M. Cardi, P. Sammartino, V. Mingarelli et al., "Cytoreduction and HIPEC in the treatment of "unconventional" secondary peritoneal carcinomatosis," World Journal of Surgical Oncology, vol. 13, no. 1, p. 305, 2015.

[13] M. Cardi, P. Sammartino, M. L. Framarino et al., "Treatment of peritoneal carcinomatosis from breast cancer by maximal cytoreduction and HIPEC: a preliminary report on 5 cases," Breast, vol. 22, no. 5, pp. 845-849, 2013.

[14] R. T. Ripley, J. L. Davis, C. D. Kemp, S. M. Steinberg, M. A. Toomey, and I. Avital, "Prospective randomized trial evaluating mandatory second look surgery with HIPEC and CRS vs. standard of care in patients at high risk of developing colorectal peritoneal metastases," Trials, vol. 11, no. 1, article 62, 2010.

[15] T. C. Chua, B. J. Moran, P. H. Sugarbaker et al., "Early- and long-term outcome data of patients with pseudomyxoma peritonei from appendiceal origin treated by a strategy of cytoreductive surgery and hyperthermic intraperitoneal chemotherapy," Journal of Clinical Oncology, vol. 30, no. 20, pp. 2449-2456, 2012.

[16] P. H. Sugarbaker, R. Alderman, G. Edwards et al., "Prospective morbidity and mortality assessment of cytoreductive surgery plus perioperative intraperitoneal chemotherapy to treat peritoneal dissemination of appendiceal mucinous malignancy," Annals of Surgical Oncology, vol. 13, no. 5, pp. 635-644, 2006.

[17] P. G. Vashi, D. Gupta, C. A. Lammersfeld et al., “The relationship between baseline nutritional status with subsequent parenteral nutrition and clinical outcomes in cancer patients undergoing hyperthermic intraperitoneal chemotherapy," Nutrition Journal, vol. 12, no. 1, p. 118, 2013.

[18] M. Valle, O. Federici, F. Carboni et al., "Postoperative infections after cytoreductive surgery and HIPEC for peritoneal carcinomatosis: proposal and results from a prospective protocol study of prevention, surveillance and treatment," European Journal of Surgical Oncology, vol. 40, no. 8, pp. 950-956, 2014.

[19] N. C. Arslan, S. Sokmen, V. Avkan-Oguz et al., "Infectious complications after cytoreductive surgery and hyperthermic intra-peritoneal chemotherapy," Surgical Infections, vol. 18, no. 2, pp. 157-163, 2017.

[20] M. Dazza, L. Schwarz, J. Coget et al., "Does intraoperative systematic bacterial sampling during complete cytoreductive surgery (CRS) with hyperthermic intraoperative peritoneal chemotherapy (HIPEC) influence postoperative treatment? A new predictive factor for postoperative abdominal infectious complications," World Journal of Surgery, vol. 40, no. 12, pp. 3035-3043, 2016.

[21] D. B. Hennessey, J. P. Burke, T. Ni-Dhonochu, C. Shields, D. C. Winter, and K. Mealy, "Preoperative hypoalbuminemia is an independent risk factor for the development of surgical site infection following gastrointestinal surgery," Annals of Surgery, vol. 252, no. 2, pp. 325-329, 2010.

[22] E. Skeie, A. M. Koch, S. Harthug et al., "A positive association between nutritional risk and the incidence of surgical site infections: a hospital-based register study," PLoS One, vol. 13, no. 5, article e0197344, 2018.

[23] J. M. Culebras, "Malnutrition in the twenty-first century: an epidemic affecting surgical outcome," Surgical Infections, vol. 14, no. 3, pp. 237-243, 2013.

[24] D. A. De Luis, J. M. Culebras, R. Aller, and J. M. Eiros-Bouza, "Surgical infection and malnutrition," Nutrición Hospitalaria, vol. 30, no. 3, pp. 509-513, 2014.

[25] B. Laky, M. Janda, J. Bauer, C. Vavra, G. Cleghorn, and A. Obermair, "Malnutrition among gynaecological cancer patients," European Journal of Clinical Nutrition, vol. 61, no. 5, pp. 642-646, 2007.

[26] D. Gupta, C. G. Lis, J. Granick, J. F. Grutsch, P. G. Vashi, and C. A. Lammersfeld, "Malnutrition was associated with poor quality of life in colorectal cancer: a retrospective analysis," Journal of Clinical Epidemiology, vol. 59, no. 7, pp. 704-709, 2006.

[27] M. M. Oken, R. H. Creech, D. C. Tormey et al., "Toxicity and response criteria of the Eastern Cooperative Oncology Group," American Journal of Clinical Oncology, vol. 5, no. 6, pp. 649656, 1982. 
[28] P. Jacquet and P. H. Sugarbaker, "Clinical research methodologies in diagnosis and staging of patients with peritoneal carcinomatosis," Cancer Treatment and Research, vol. 82, pp. 359-374, 1996.

[29] United States Department of Public Health and Human Services, NIH-NCI: common terminology criteria for adverse effects (CTCAE) v 5.0. National Cancer Institute, 2017, https://ctep. cancer.gov/protocoldevelopment/electronic_applications/docs/ CTCAE_v5_quick_reference_5x7.pdf.

[30] World Health Organization, WHO Handbook for Reporting Results of Cancer Treatment, WHO, Geneva, 1979.

[31] D. Baratti, S. Kusamura, E. Mingrone, M. R. Balestra, B. Laterza, and M. Deraco, "Identification of a subgroup of patients at highest risk for complications after surgical cytoreduction and hyperthermic intraperitoneal chemotherapy," Annals of Surgery, vol. 256, no. 2, pp. 334-341, 2012.

[32] O. Glehen, D. Osinsky, E. Cotte et al., "Intraperitoneal chemohyperthermia using a closed abdominal procedure and cytoreductive surgery for the treatment of peritoneal carcinomatosis: morbidity and mortality analysis of 216 consecutive procedures," Annals of Surgical Oncology, vol. 10, no. 8, pp. 863869, 2003.

[33] R. Younan, S. Kusamura, D. Baratti, A.-S. Cloutier, and M. Deraco, "Morbidity, toxicity, and mortality classification systems in the local regional treatment of peritoneal surface malignancy," Journal of Surgical Oncology, vol. 98, no. 4, pp. 253-257, 2008.

[34] F. Quenet, D. Elias, L. Roca et al., "A UNICANCER phase III trial of hyperthermic intra-peritoneal chemotherapy (HIPEC) for colorectal peritoneal carcinomatosis (PC): PRODIGE 7," Journal of Clinical Oncology, vol. 36, 18_suppl, p. LBA3503, 2018, suppl.

[35] A. Weimann, M. Braga, L. Harsanyi et al., "ESPEN guidelines on enteral nutrition: surgery including organ transplantation," Clinical Nutrition, vol. 25, no. 2, pp. 224-244, 2006.

[36] J. T. Mullen, D. W. Moorman, and D. L. Davenport, "The obesity paradox: body mass index and outcomes in patients undergoing nonbariatric general surgery," Annals of Surgery, vol. 250, no. 1, pp. 166-172, 2009.

[37] M. Ri, S. Aikou, and Y. Seto, "Obesity as a surgical risk factor," Annals of Gastroenterological Surgery, vol. 2, no. 1, pp. 13-21, 2018.

[38] N. J. Gusani, S. W. Cho, C. Colovos et al., “Aggressive surgical management of peritoneal carcinomatosis with low mortality in a high-volume tertiary cancer center," Annals of Surgical Oncology, vol. 15, no. 3, pp. 754-763, 2008.

[39] B. Ataseven, A. du Bois, A. Reinthaller et al., "Pre-operative serum albumin is associated with post-operative complication rate and overall survival in patients with epithelial ovarian cancer undergoing cytoreductive surgery," Gynecologic Oncology, vol. 138, no. 3, pp. 560-565, 2015.

[40] P. Caironi, G. Tognoni, S. Masson et al., "Albumin replacement in patients with severe sepsis or septic shock," The New England Journal of Medicine, vol. 370, no. 15, pp. 1412-1421, 2014.

[41] A. Weimann, "Guideline of the German Society for Nutritional Medicine (DGEM) in cooperation with the GESKES, the AKE, the DGCH, the DGAI and the DGAV clinical nutrition in surgery," Aktuel Ernahrungsmed, vol. 38, pp. e155e197, 2013.

[42] S. Uccella, M. C. Mele, L. Quagliozzi et al., "Assessment of preoperative nutritional status using BIA-derived phase angle
(PhA) in patients with advanced ovarian cancer: correlation with the extent of cytoreduction and complications," Gynecologic Oncology, vol. 149, no. 2, pp. 263-269, 2018.

[43] National Cancer Centre, Singapore, "Perioperative immunonutrition for patients undergoing CRS and HIPEC," Clinical Trials Identifier NCT03430128. https://clinicaltrials.gov/ct2/ show/NCT03430128.

[44] C. Raspé, L. Flöther, R. Schneider, M. Bucher, and P. Piso, "Best practice for perioperative management of patients with cytoreductive surgery and HIPEC," European Journal of Surgical Oncology, vol. 43, no. 6, pp. 1013-1027, 2017.

[45] J. W. Drover, R. Dhaliwal, L. Weitzel, P. E. Wischmeyer, J. B. Ochoa, and D. K. Heyland, "Perioperative use of arginine-supplemented diets: a systematic review of the evidence," Journal of the American College of Surgeons, vol. 212, no. 3, pp. 385-399.e1, 2011.

[46] G. S. Sica, C. Fiorani, C. Stolfi et al., "Peritoneal expression of matrilysin helps identify early post-operative recurrence of colorectal cancer," Oncotarget, vol. 6, no. 15, pp. 1340213415, 2015. 


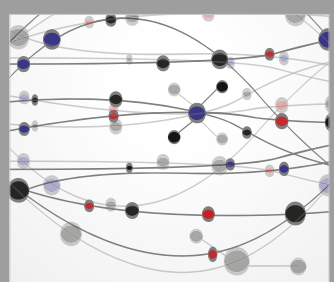

The Scientific World Journal
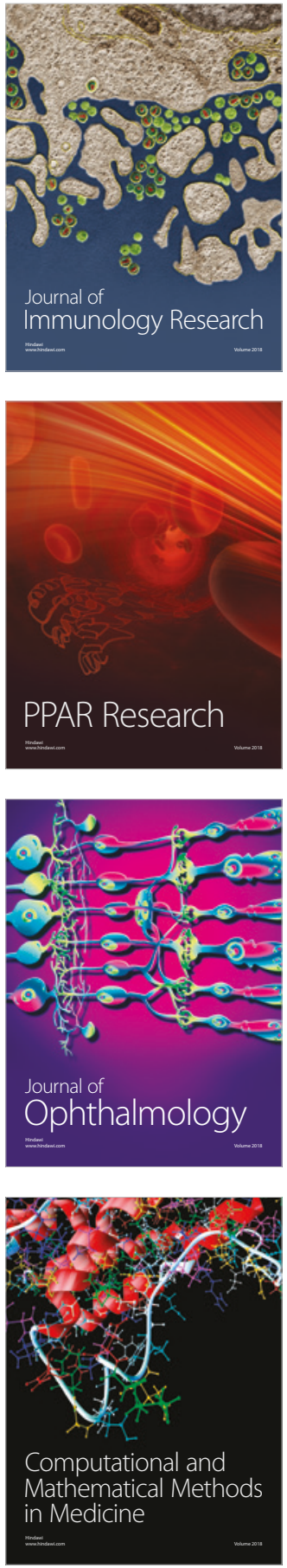

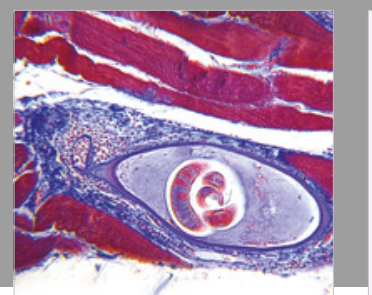

Gastroenterology Research and Practice

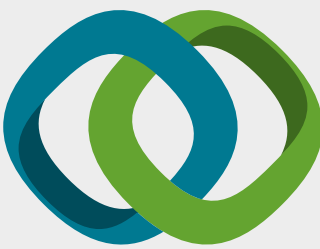

\section{Hindawi}

Submit your manuscripts at

www.hindawi.com
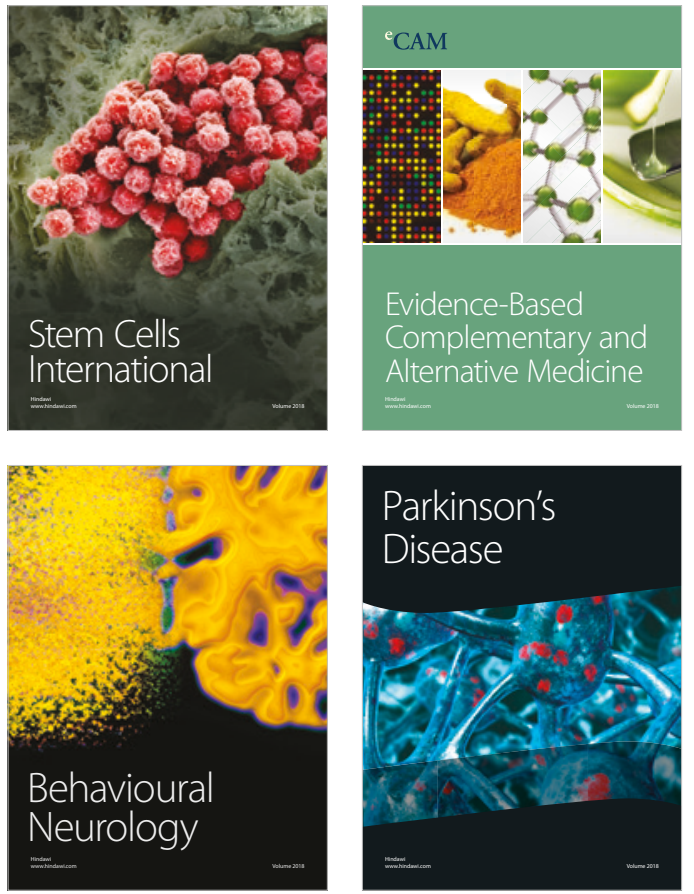

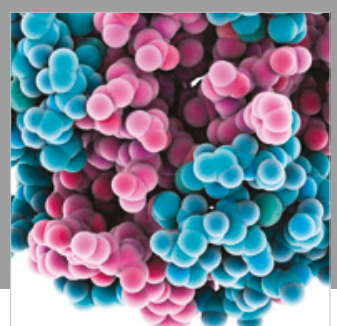

ournal of

Diabetes Research

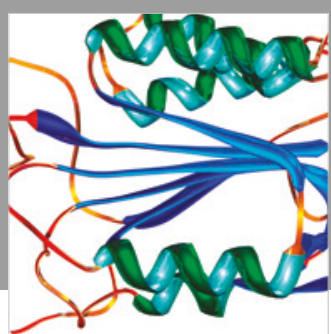

Disease Markers
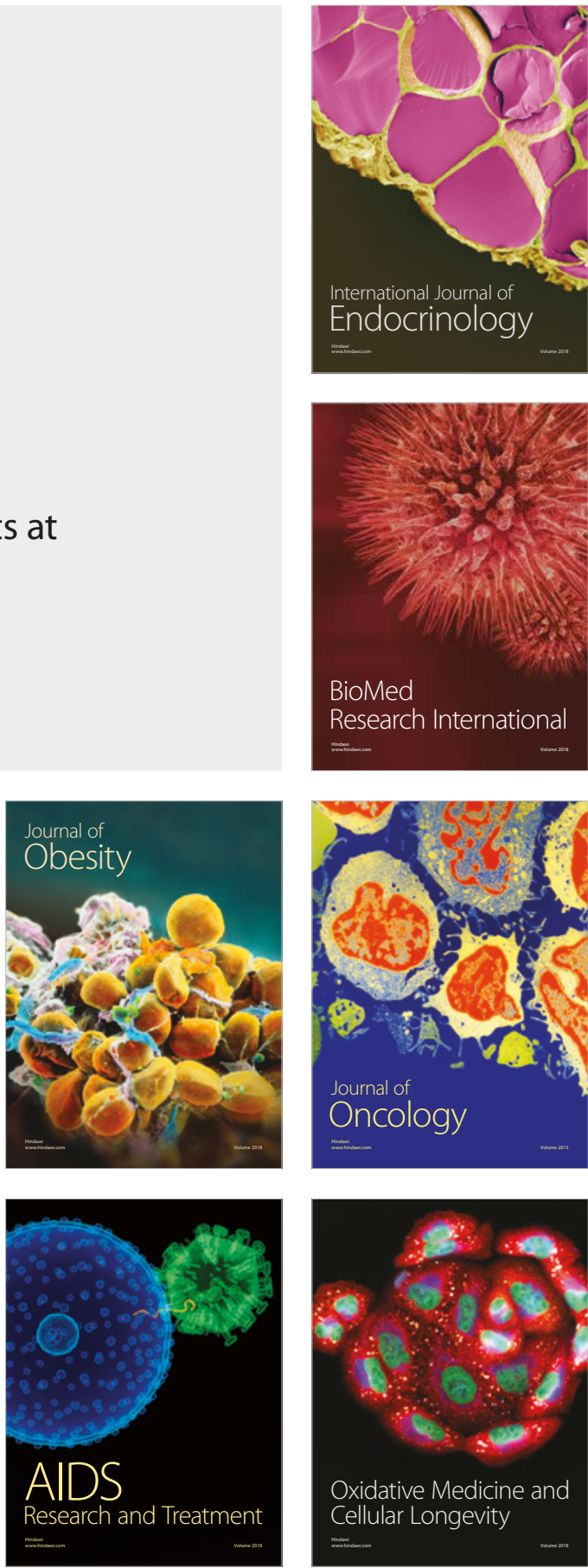